\title{
Programmable Permeability of Metal-Phenolic Network Microcapsules
}

\author{
Jingqu Chen, Shuaijun Pan, Jiajing Zhou, Qi-Zhi Zhong, Yijiao Qu, Joseph J. Richardson, and Frank \\ Caruso*
}

ARC Centre of Excellence in Convergent Bio-Nano Science and Technology, and the Department of Chemical Engineering, The University of Melbourne, Parkville, Victoria 3010, Australia

\begin{abstract}
Developing materials with programmable permeability for cargo encapsulation and release is challenging but important in a number of fields including drug delivery and sensing. Metal-phenolic networks (MPNs) are an emerging class of hybrid coordination materials with $\mathrm{pH}$-responsiveness and modularity that can be engineered into functional thin films for diverse applications. Herein, we engineer MPN-based microcapsules with a dynamic gating mechanism by adjusting the intermolecular interactions in the capsules. Altering the choice of building blocks and precursor ratio provides an intrinsic and modular means of tailoring capsule size and permeability. Alternatively, regulating the $\mathrm{pH}$ of the environment, and thereby the protonation states of MPNs, extrinsically enables capsules to switch between highly permeable ( $>90 \%$ of capsules permeable at $\mathrm{pH} 9)$ and near-impermeable $(<20 \%$ at $\mathrm{pH} 3)$ states. These findings provide insights into the dynamic nature of MPNs and offer a route to engineer smart delivery systems and selective gating materials.
\end{abstract}

\section{INTRODUCTION}

Designing "programmable" thin films and membranes with selective and dynamic gating properties has received extensive attention in numerous fields, such as sensing and separations, ${ }^{1-3}$ molecular filtration, ${ }^{4-6}$ drug delivery, ${ }^{7,8}$ and nano/micro-reactors. ${ }^{9}$ State-of-the-art approaches for engineering thin films with selective permeability include multilayer assembly with specific polymer combinations, ${ }^{10-13}$ surface wettability modifications, ${ }^{14}$ host-guest interactions, ${ }^{15,16}$ and tuning of environmental conditions (e.g., light, ${ }^{17}$ temperature, ${ }^{18,19}$ and ionic strength ${ }^{7}$ ). However, it is challenging to engineer thin films where the permeability can be controlled both intrinsically (molecular composition changes) and extrinsically (environmental changes) in a modular approach in aqueous environments. Moreover, reversibly switching between highly permeable and impermeable states without requiring disassembly or degradation often necessitates covalent cross-linking of films. ${ }^{20}$ For example, using thermal oxidative cross-linking and thiol-ene-based "click" chemistry can improve the selectivity of molecular sieving. ${ }^{21,22}$ Coordination chemistry involving organic ligands and metal ions enables dynamic manipulations of nano/microstructures through both the choice of building blocks and external environmental conditions, ${ }^{23-25}$ thereby offering a viable pathway to achieve tailorable cargo loading-release profiles.

Metal-phenolic networks (MPNs) are an emerging class of metal-organic materials that can be deposited as thin films on a broad range of substrates (e.g., colloidal particles, planar substrates, and bacteria/cells). ${ }^{25-28}$ Previously, we demonstrated the engineering of MPN microcapsules that were moderately permeable,${ }^{25}$ highly permeable,${ }^{29}$ or nearly impermeable,${ }^{30}$ by adopting distinct assembly kinetics (e.g., by controlling the reactive species). However, the ability of these systems to switch permeability and an understanding of the parameters that influence and enable tuning of MPN capsule permeability remains unexplored. Such information is important for the development of MPN materials for various applications including drug delivery and separations.
In the present study, we assemble a series of MPN capsules and investigate the effect of intrinsic (i.e., building blocks) and extrinsic (i.e., environmental $\mathrm{pH}$ ) parameters on the selective gating of MPN microcapsules. MPN capsules are assembled from sacrificial polystyrene (PS) particle templates using naturally occurring phenolic ligands (e.g., tannic acid (TA), gallic acid (GA), and pyrogallol (PG); see Figure S1 in Supporting Information) and various metal ions (e.g., $\mathrm{Fe}^{\mathrm{III}}, \mathrm{Al}^{\mathrm{III}}$, and $\mathrm{Cu}^{\mathrm{II}}$ ). The complexation states of the coordinated ligands and metal ions involve mono, bis, or tris forms depending on the $\mathrm{pH}$ used to assemble the films (Figure 1a). ${ }^{25}$ For MPN assembly, the coordination between catechol/galloyl groups and metal ions is the driving force, in conjunction with hydrogen bonding and $\pi-\pi$ stacking interactions. Notably, intermolecular repulsion may also arise from the abundant phenolic groups present in the system when deprotonated (e.g., high $\mathrm{pH}$ ). Therefore, the choice of phenolic and metal building blocks, precursor ratio, and $\mathrm{pH}$ conditions strongly influences the intermolecular dynamics after template removal, giving rise to different network microstructures and thereby capsule permeability (Figure 1b). For example, we herein demonstrate that constructing MPNs from metal ions with low binding affinities to the phenolic ligands (e.g., $\mathrm{Al}^{\mathrm{III}}$ and $\mathrm{Cu}^{\mathrm{II}}$ ) can provide additional available sites for the other intermolecular attractions after template removal, leading to dense packing and reduced permeability. Alternatively, we show that MPNs prepared from high $\mathrm{pH}$ intrinsically have increased intermolecular repulsions (due to deprotonation), displaying a lower degree of molecular packing and thus increased permeability. Notably, our in situ analysis reveals that MPN capsules switch between "open" and "closed" states in response to $\mathrm{pH}$ changes, displaying programmable/dynamic cargo encapsulation and release profiles. These findings have implications for the design of future metal-organic materials.

\section{RESULTS AND DISCUSSION}


a

Phenolic

ligand
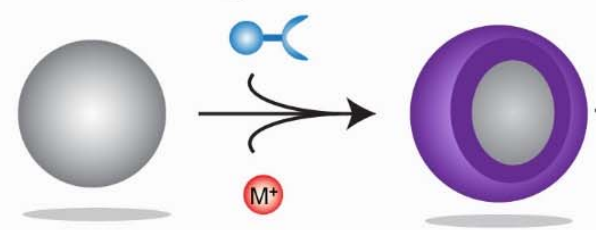

Template removal

PS

template

Metal ion

PS@MPN

b

b Low

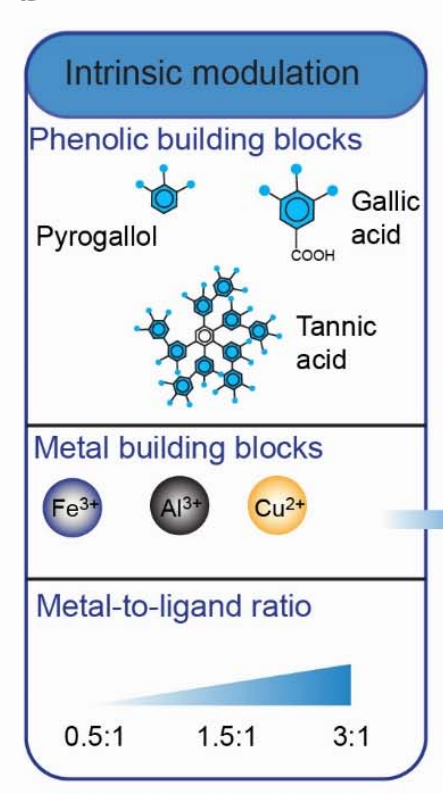

Low permeability
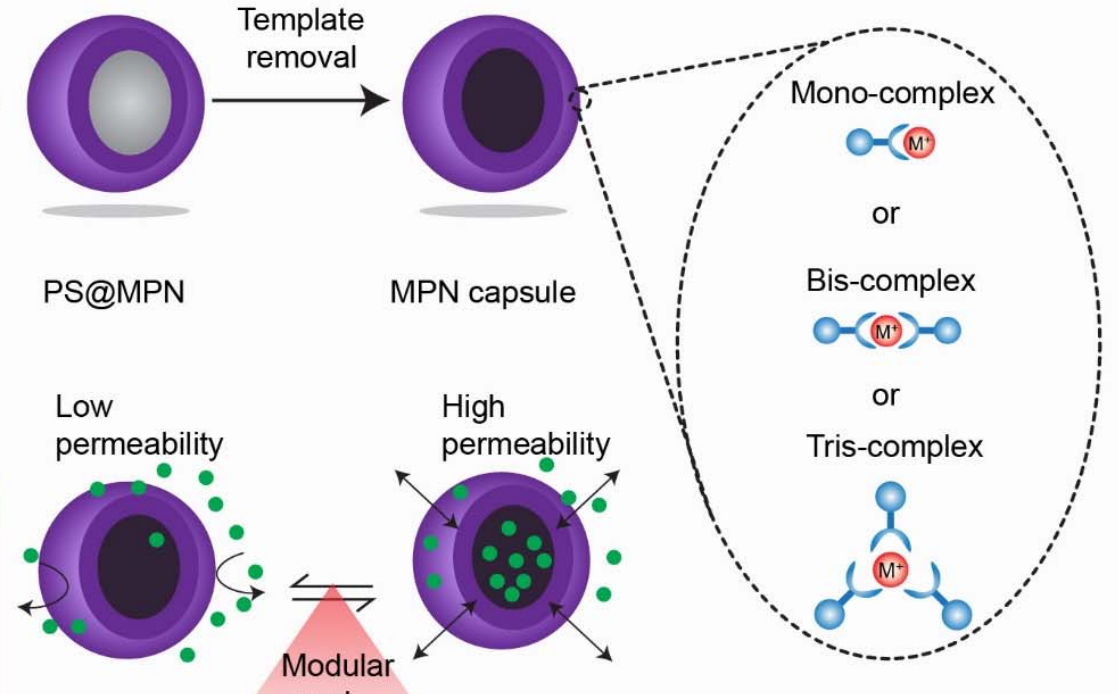

MPN capsule

$$
\text { and }
$$

programmable

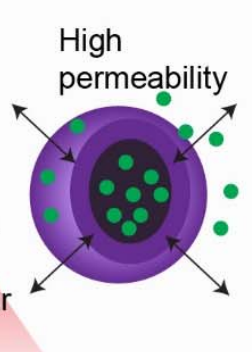

or

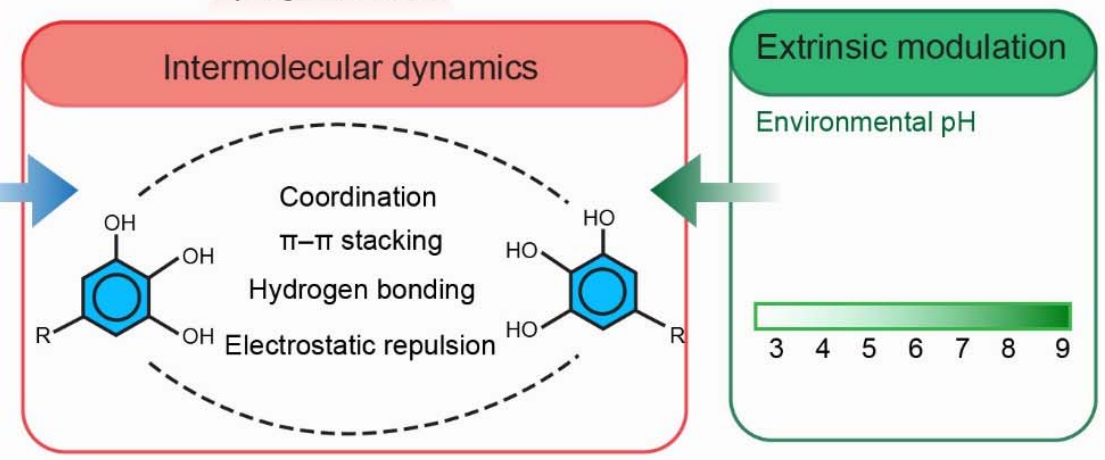

Morphology

C

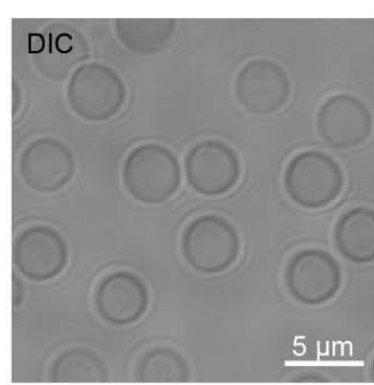

Thickness

d

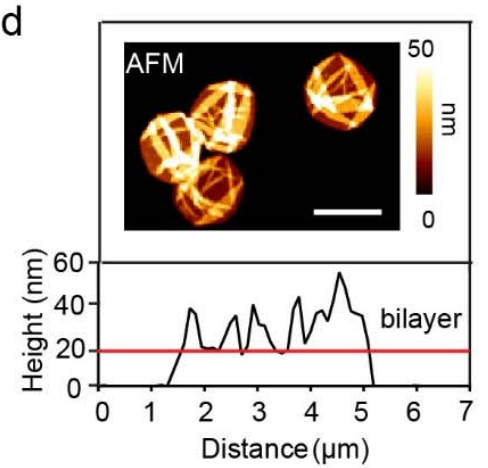

Permeability

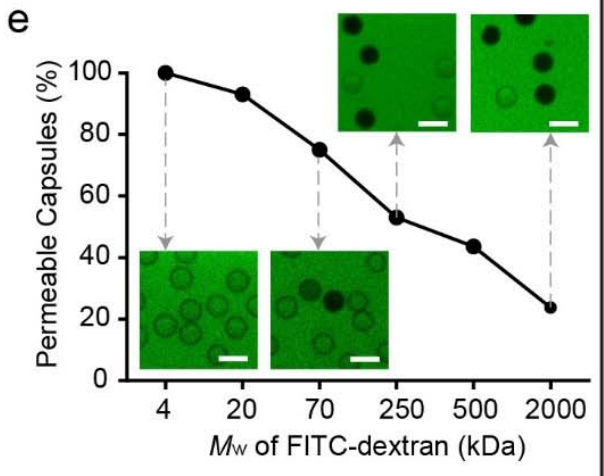

Figure 1. (a) Schematic of the assembly of phenolic ligands and metal ions to form an MPN film on a PS template particle (PS@MPN), followed by the formation of an MPN capsule after template removal. (b) Schematic diagram of programming the permeability of MPN capsules by adjusting intermolecular dynamics through both intrinsic and extrinsic modulations. (c) DIC microscopy image of TA/Fe ${ }^{\mathrm{III}}$ capsules assembled at pH 5. (d) AFM image and representative line profile of height measurement (indicated by the red arrow) of TA/Fe ${ }^{\mathrm{III}}$ capsules. Scale bar is $3 \mu \mathrm{m}$. (e) Percentage of permeable capsules as a function of the $M_{\mathrm{w}}$ of FITC-dextran. Inset pictures are representative confocal laser scanning microscopy (CLSM) images of the capsules; 100 capsules of each sample were measured. Capsules with dark interiors were considered to be impermeable, whereas those with interiors with the same fluorescence intensity as the outer FITC-dextran background were considered to be permeable. Scale bars are $5 \mu \mathrm{m}$.

As a proof-of-concept and experimental controls, TA/Fe $\mathrm{FII}^{\mathrm{III}}$ films were deposited on sacrificial PS particles $(3.6 \pm 0.2 \mu \mathrm{m})$ via coordination-driven assembly at $\mathrm{pH} 5$ (using a Fe $\mathrm{III}_{\text {-to-TA molar }}$ ratio of 1.5:1 as per our protocol ${ }^{25}$ ) to form PS@TA/Fe $\mathrm{FII}^{\mathrm{III}}$ core- 
shell particles. Subsequent core (PS) removal yielded TA/Fe ${ }^{\mathrm{III}}$ capsules. The monodisperse, spherical capsules observed from differential interference contrast (DIC) microscopy highlights the stability of the free-standing networks after template removal (Figure 1c). Atomic force microscopy (AFM) showed that the collapsed (air-dried) capsules had a shell (monolayer) thickness of $\sim 10 \mathrm{~nm}$ (Figure 1d). The appearance of the characteristic ligand-to-metal charge transfer band with a peak around $570 \mathrm{~nm}$ wavelength suggests the existence of ligand-metal coordination chemistry (Figure S2). The permeability of TA/Fe $\mathrm{FII}^{\mathrm{III}}$ capsules was investigated by incubating them with a series of fluorescein isothiocyanate-labeled dextran molecules (FITC-dextran) with different molecular weights $\left(M_{\mathrm{w}}\right)$. As shown in Figure 1e, the $\mathrm{TA} / \mathrm{Fe}^{\mathrm{III}}$ capsules displayed a $M_{\mathrm{w}}$-dependent permeability, i.e., from permeable to near-impermeable as $M_{\mathrm{w}}$ increased. Specifically, more than $90 \%$ of the $\mathrm{TA} / \mathrm{Fe}^{\mathrm{III}}$ capsules were permeable when the $M_{\mathrm{w}}$ is low ( $<20 \mathrm{kDa}$ ), whereas $\sim 80 \%$ capsules became near-impermeable when the $M_{\mathrm{w}}$ is high (i.e., $2000 \mathrm{kDa}$ ).

As MPNs have a high degree of modularity in terms of the choice of building blocks, ${ }^{26,27}$ we investigated the influence of different aspects of MPN assembly on the permeability of the corresponding capsules. Specifically, FITC-dextran with intermediate $M_{\mathrm{w}}(70 \mathrm{kDa})$ was used to investigate the effects of metalto-ligand molar ratio, metal and ligand type, and environmental $\mathrm{pH}$. The effect of varying the precursor molar ratio $\left(n\left(\mathrm{Fe}^{\mathrm{III}}\right)\right.$ : $n$ (TA) of $0.5: 1,1.5: 1$ and $3: 1)$ was examined while the amount of TA and the preparation $\mathrm{pH}$ were both fixed. Increasing the $\mathrm{Fe}^{\mathrm{III}} / \mathrm{TA}$ molar ratio did not significantly change the capsule size or shell thickness (Figure S3a). However, it significantly altered the permeability of the capsules. When the ratio was $0.5: 1$, only $20 \%$ of the capsules were permeable. As the molar ratio increased to $1.5: 1$, the permeability increased to $\sim 75 \%$ and reached $100 \%$ as the molar ratio was increased further to $3: 1$ (Figure 2a, $2 \mathrm{~b}$ ). Coordinating TA with a larger proportion of $\mathrm{Fe}^{\mathrm{III}}$ enlarged the size of the building blocks, which yielded capsules with more nanoscale defects (Figure S3b), as reflected by the root-meansquare roughness value, translating to higher permeability.

The effect of metal ion on capsule permeability was then examined. TA/Fe ${ }^{\mathrm{III}}, \mathrm{TA} / \mathrm{Al}^{\mathrm{III}}$, and $\mathrm{TA} / \mathrm{Cu}^{\mathrm{II}}$ capsules were assembled at the same $\mathrm{pH}$ and metal-to-TA molar ratio of 1.5:1. Capsules assembled from $\mathrm{Cu}^{\mathrm{II}}$ and $\mathrm{Al}^{\mathrm{III}}$ were $\sim 3 \mathrm{~nm}$ thinner than those assembled from $\mathrm{Fe}^{\mathrm{III}}$ (Figure S4). Relative to the TA/Fe ${ }^{\mathrm{III}}$ capsules, the TA/Al ${ }^{\mathrm{III}}$ capsules were less permeable - only $20 \%$ of TA/Al ${ }^{\mathrm{III}}$ capsules were permeable to FITC-dextran and the permeability decreased further to $2 \%$ when $\mathrm{Cu}^{\mathrm{II}}$ metal ions were used (Figure 2c). This trend was attributed to capsule shrinkage (Figure 2d). The TA/Fe ${ }^{\mathrm{III}}$ capsules had a diameter of $3.5 \pm 0.2 \mu \mathrm{m}$, which was comparable to the size of the PS template $(3.6 \pm 0.2 \mu \mathrm{m})$; the strong binding affinity between $\mathrm{Fe}^{\mathrm{III}}$ and the catechol/galloyl groups of TA produced stable $\mathrm{TA} / \mathrm{Fe}^{\mathrm{III}}$ networks.

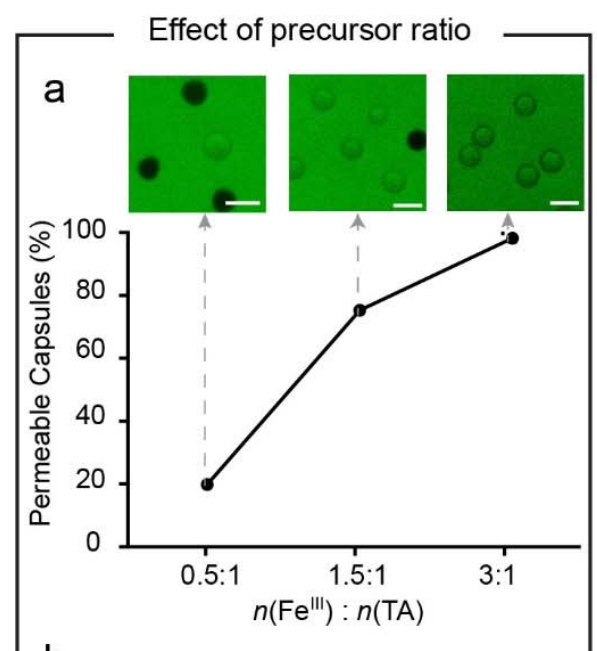

b

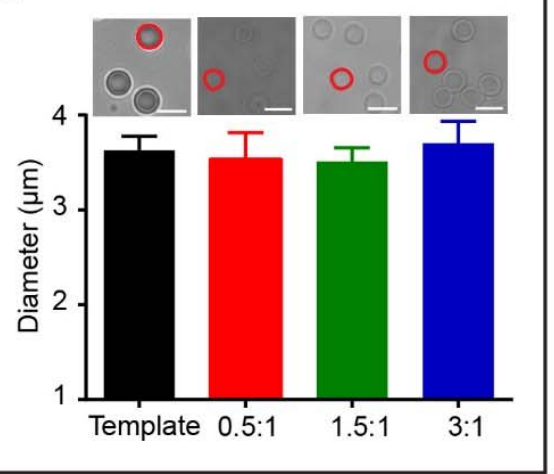

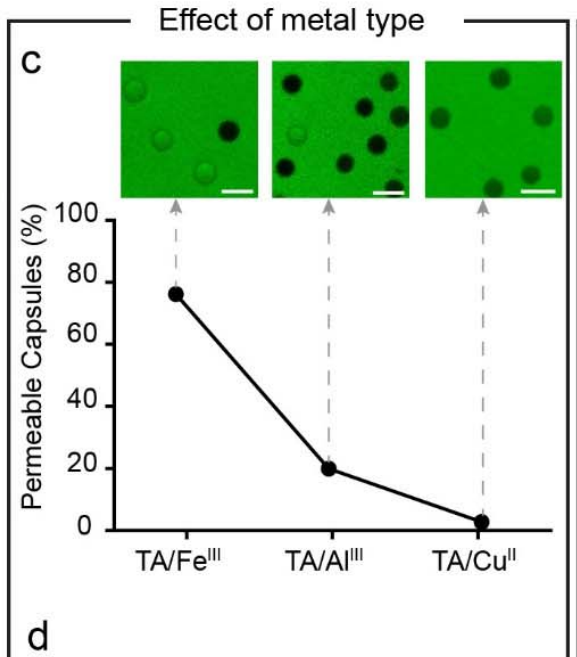

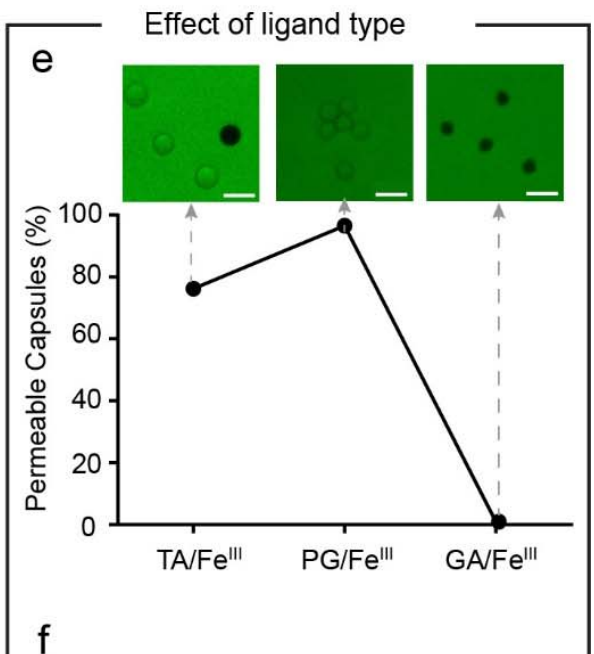

f

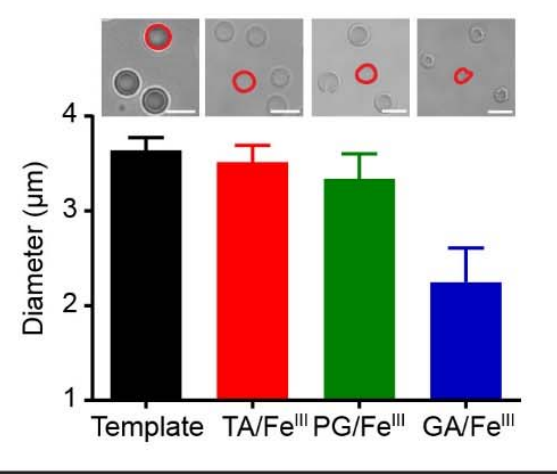

Figure 2. Effect of intrinsic factors of MPN capsules on (a, c, e) capsule permeability to FITC-dextran with a $M_{\mathrm{w}}$ of $70 \mathrm{kDa}$ (inset pictures are corresponding CLSM images) and (b, $\mathrm{d}, \mathrm{f}$ ) capsule diameter after template removal (inset pictures are corresponding DIC images). Capsules are constructed from TA/Fe $\mathrm{Fe}^{\mathrm{III}}$ with different $\mathrm{Fe}^{\mathrm{III}}$-to-TA molar ratios $(\mathrm{a}, \mathrm{b})$, TA and different metals $(\mathrm{c}, \mathrm{d})$, or $\mathrm{Fe}^{\mathrm{III}}$ and different phenolic ligands (e, f). For the analyses, 100 capsules of each sample were measured. Scale bars are $5 \mu \mathrm{m}$. 
a

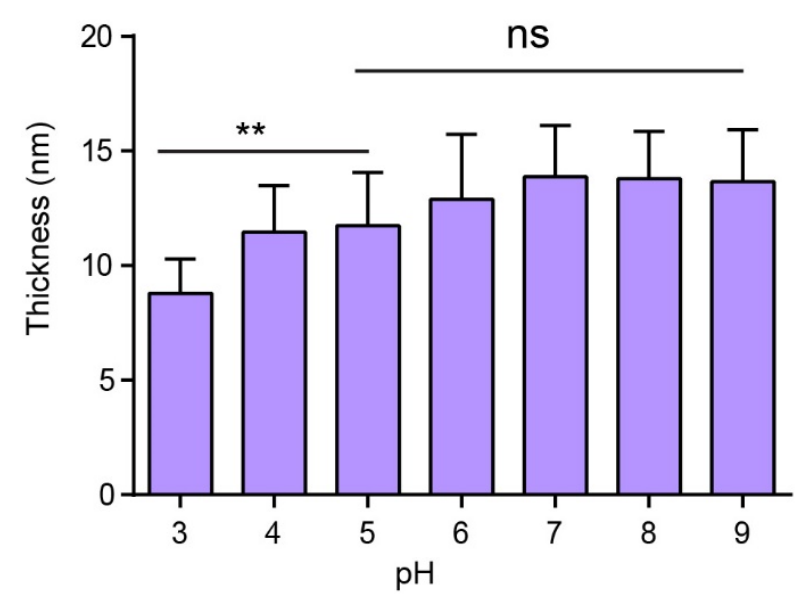

C

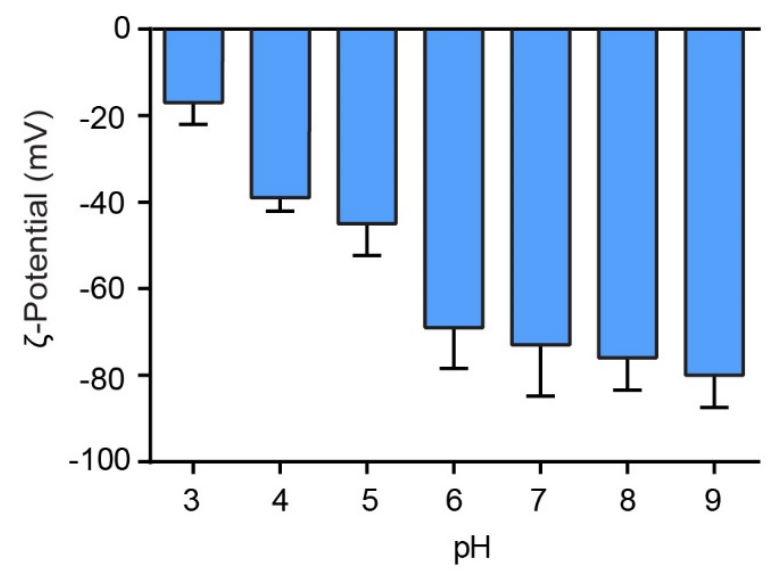

b

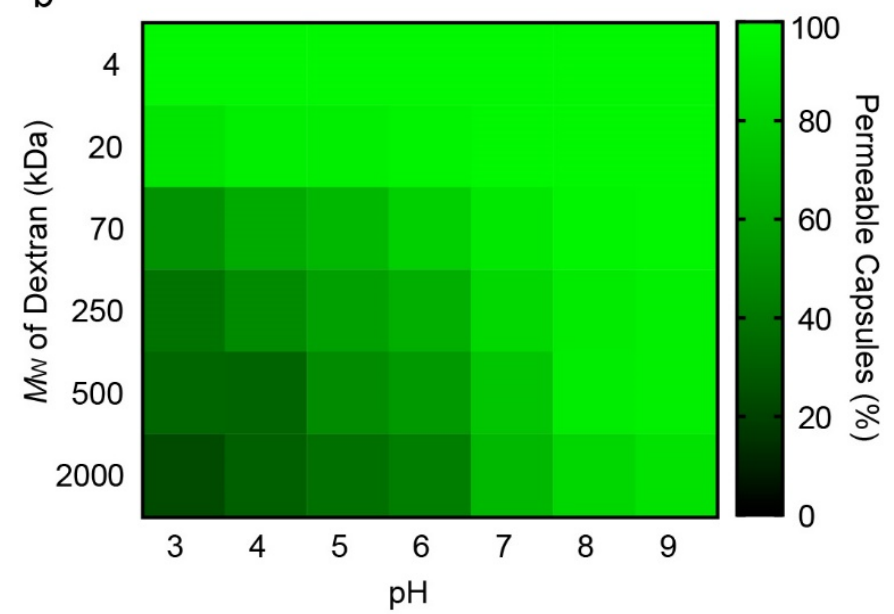

d

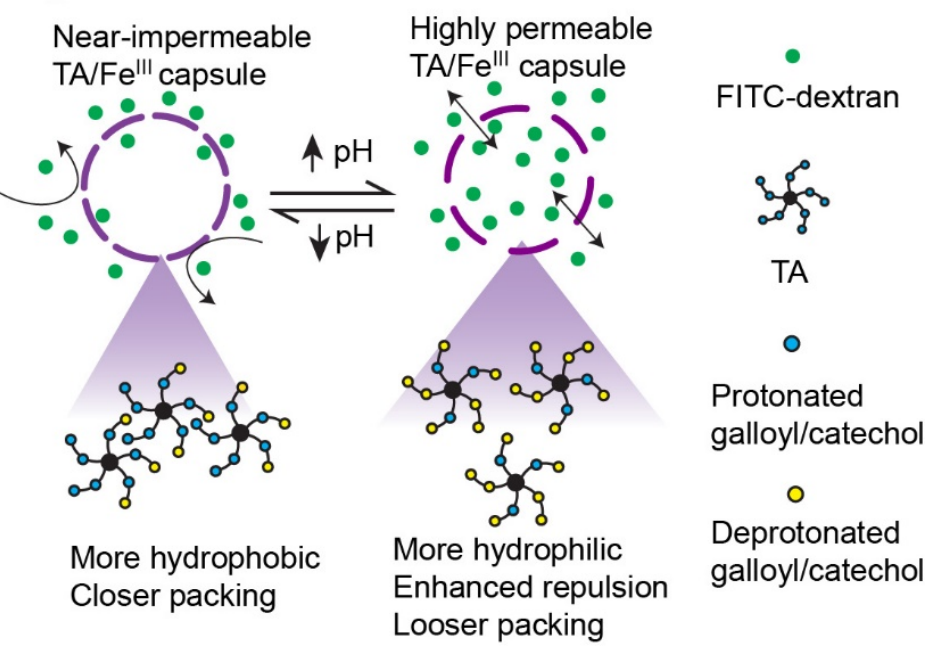

Figure 3. (a) Single wall thickness of $\mathrm{TA} / \mathrm{Fe}^{\mathrm{III}}$ capsules prepared at different $\mathrm{pH}(\mathrm{pH} 3-9)$. (b) Heat map showing the percentage of TA/Fe $\mathrm{F}^{\mathrm{III}}$ capsules permeable to FITC-dextran $\left(M_{\mathrm{w}}=4-2000 \mathrm{kDa}\right)$ at different $\mathrm{pH} ; 100$ capsules of each sample were measured. (c) $\zeta$-Potential of the $\mathrm{TA} / \mathrm{Fe}^{\mathrm{III}}$ capsules following dispersion at different $\mathrm{pH}$. (d) Schematic of the effect of $\mathrm{pH}$ on capsule permeability.

In contrast, $\mathrm{Al}^{\mathrm{III}}$ and $\mathrm{Cu}^{\mathrm{II}}$ have a significantly lower binding affinity to $\mathrm{TA},{ }^{26}$ which resulted in a lower cross-linking density of the network and reduced steric hindrance between TA molecules. Hence, more sites were available for intermolecular attraction on the TA molecules, which drove reorganization of the wall structure after template removal. This caused the $\mathrm{TA} / \mathrm{Al}^{\mathrm{III}}$ and $\mathrm{TA} / \mathrm{Cu}^{\mathrm{II}}$ capsules to shrink to $3.1 \pm 0.2 \mu \mathrm{m}(11 \%$ shrinkage relative to $\mathrm{TA} / \mathrm{Fe}^{\mathrm{III}}$ capsules $)$ and $2.8 \pm 0.2 \mu \mathrm{m}(20 \%$ shrinkage relative to $\mathrm{TA} / \mathrm{Fe}^{\mathrm{III}}$ capsules), respectively, after PS removal (Figure $2 \mathrm{~d})$.

The effect of phenolic ligands on capsule permeability was also examined. Unlike TA, a dendrimer-like molecule, PG and GA are smaller phenolic ligands with fewer binding sites but with the same binding groups (i.e., galloyl groups) (Figure S1). $\mathrm{TA} / \mathrm{Fe}^{\mathrm{III}}, \mathrm{PG} / \mathrm{Fe}^{\mathrm{III}}$, and $\mathrm{GA} / \mathrm{Fe}^{\mathrm{IIII}}$ capsules were prepared with the same molar ratio of phenolic groups. Compared with $\mathrm{TA} / \mathrm{Fe}^{\mathrm{III}}$ and $\mathrm{PG} / \mathrm{Fe}^{\mathrm{III}}$ capsules with a single wall thickness of $\sim 12 \mathrm{~nm}$ (12.9 \pm 4.0 and $12.4 \pm 3.6 \mathrm{~nm}$, respectively), GA/Fe ${ }^{\mathrm{III}}$ capsules featured thinner walls $(6.8 \pm 1.6 \mathrm{~nm})$ (Figure S5). Despite both $\mathrm{PG}$ and GA being simple phenolic ligands, the GA/Fe ${ }^{\mathrm{III}}$ capsules were less permeable $(\sim 0 \%)$ than the $\mathrm{PG} / \mathrm{Fe}^{\mathrm{III}}$ capsules $(95 \%)$ (Figure $2 \mathrm{e}$ ). Among all capsule types studied, GA/Fe $\mathrm{Fe}^{\mathrm{III}}$ capsules exhibited the lowest permeability. Interestingly, only the $\mathrm{GA} / \mathrm{Fe}^{\mathrm{III}}$ capsules shrank after template removal (to $2.2 \pm 0.4 \mu \mathrm{m}$, i.e., $37 \%$ shrinkage relative to $\mathrm{TA} / \mathrm{Fe}^{\mathrm{III}}$ capsules) (Figure $2 \mathrm{f}$ ). A comparable degree of metal-phenolic coordination is expected in the $\mathrm{TA} / \mathrm{Fe}^{\mathrm{III}}, \mathrm{PG} / \mathrm{Fe}^{\mathrm{III}}$, and $\mathrm{GA} / \mathrm{Fe}^{\mathrm{III}}$ capsules as the synthesis conditions were controlled so that the number of galloyl groups is the same. However, the carboxylic groups on GA could potentially provide additional driving forces (e.g., hydrogen bonding, salt bridging of carboxylate) for capsule shrinkage.

As $\mathrm{pH}$-responsive multivalent coordination is a characteristic property of MPNs, ${ }^{25}$ the effect of $\mathrm{pH}$ was explored, as an extrinsic factor influencing capsule permeability. TA/Fe ${ }^{\mathrm{III}}$ capsules were prepared at varying solution $\mathrm{pH}$, from 3 to 9 . The thickness of the capsules prepared at $\mathrm{pH} 3$ was $8.8 \pm 1.5 \mathrm{~nm}$, which increased to $12.9 \pm 2.8 \mathrm{~nm}$ at $\mathrm{pH} 6$ and plateaued thereafter with a further increase in the $\mathrm{pH}$ (Figure 3a). A higher $\mathrm{pH}$ is likely to result in the formation of larger complexes when depositing on the template surface (Figure S6). The heat map in Figure 3b 
a

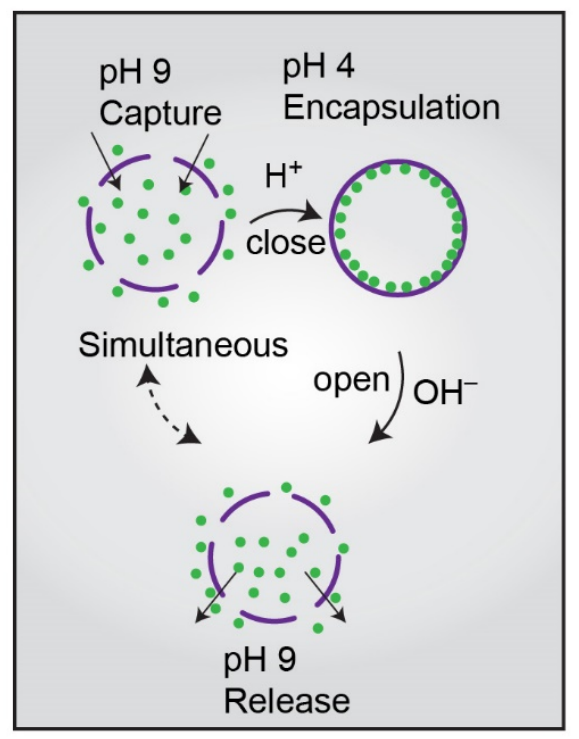

C

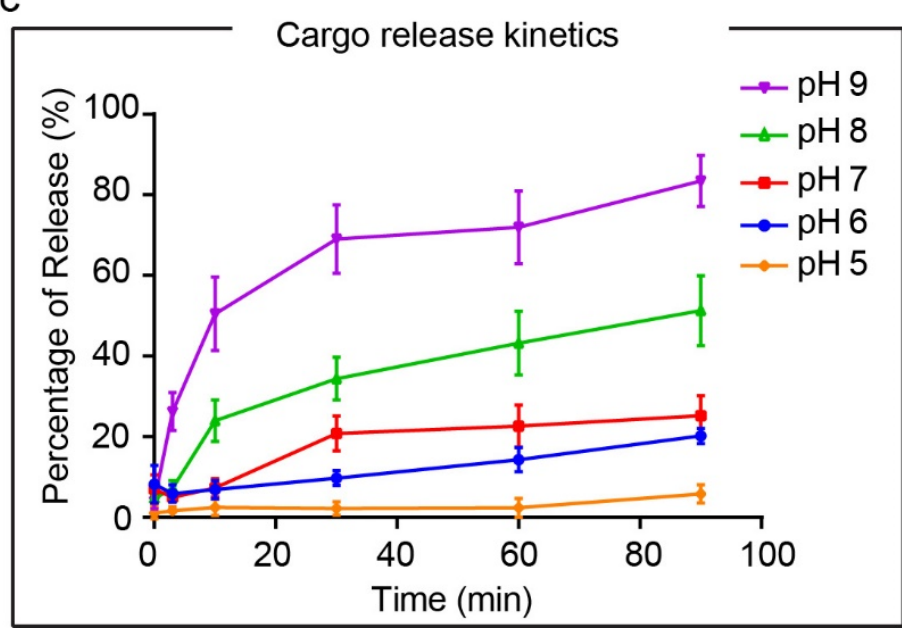

b

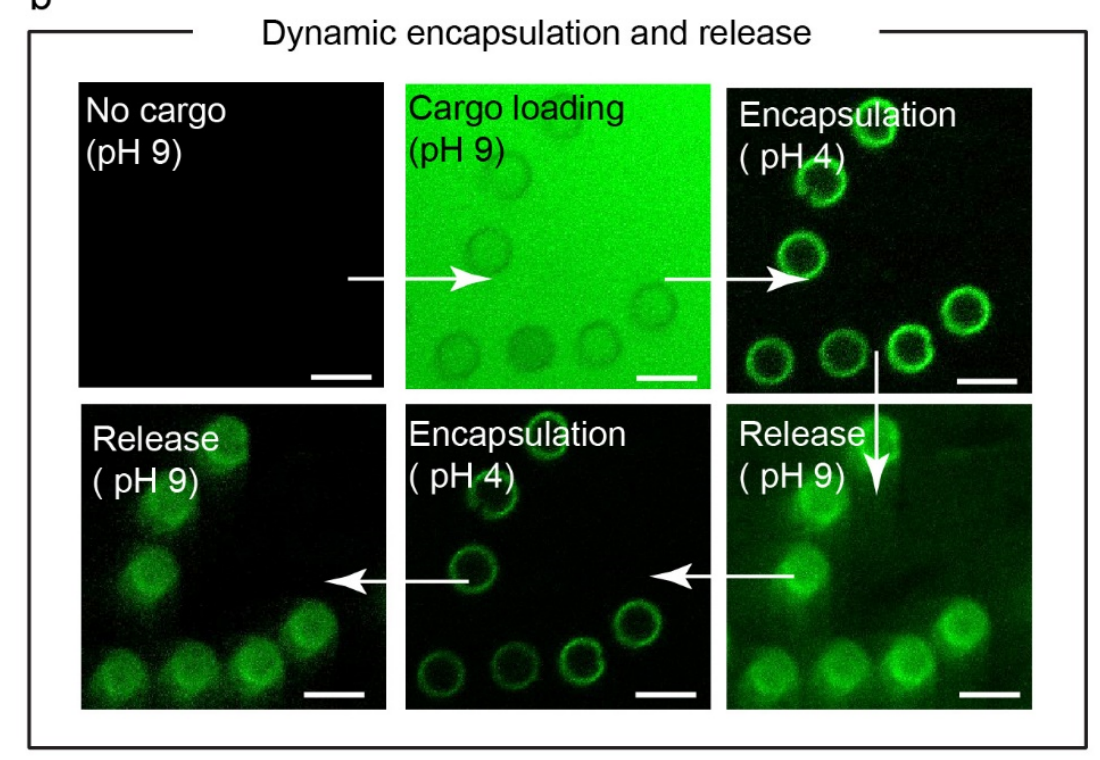

d

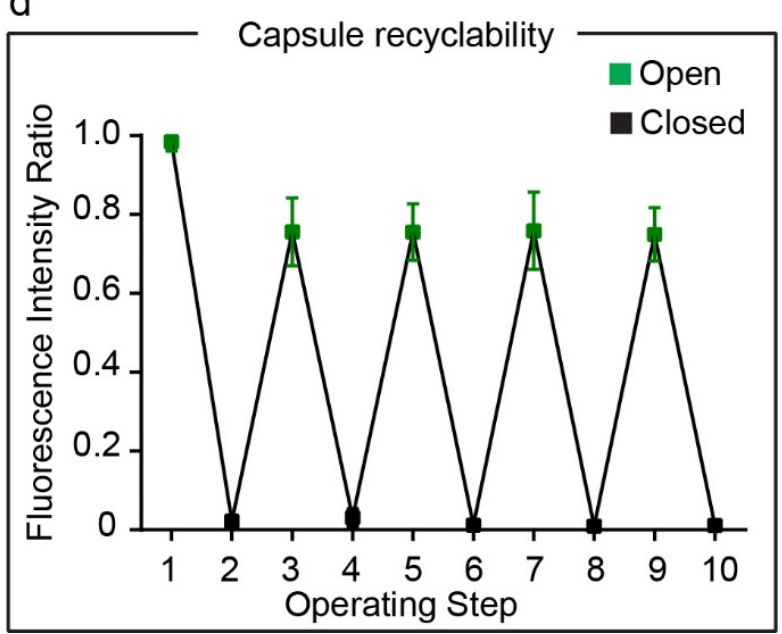

Figure 4. (a) Schematic diagram of $\mathrm{pH}$-regulated switchable permeability of $\mathrm{TA} / \mathrm{Fe}^{\mathrm{III}}$ capsules for cargo encapsulation and release. (b) Representative CLSM images of the encapsulation and release of FITC-dextran $\left(M_{\mathrm{w}} 250 \mathrm{kDa}\right)$ from TA/Fe $\mathrm{F}^{\mathrm{III}}$ capsules at $\mathrm{pH} 4$ and 9 . Scale bars are $5 \mu \mathrm{m}$. (c) Time course plots of $\mathrm{pH}$-dependent FITC-dextran release from TA/Fe $\mathrm{F}^{\mathrm{III}}$ over 90 min. (d) Recyclability of TA/Fe $\mathrm{F}^{\mathrm{III}}$ capsules represented by the ratio of the mean fluorescence intensity measured at the capsule center to that measured on the rim as a function of operating time; 100 capsules of each sample were measured.

shows the relationship between $\mathrm{pH}$ and permeability to FITCdextran at varying $M_{\mathrm{w}}$. Raising the $\mathrm{pH}$ increased capsule permeability. For instance, only $\sim 35 \%$ of the $\mathrm{TA} / \mathrm{Fe}^{\mathrm{III}}$ capsules prepared at $\mathrm{pH} 3$ were permeable to FITC-dextran of $M_{\mathrm{w}}$ of 250 $\mathrm{kDa}$, whereas $\sim 90 \%$ of the $\mathrm{TA} / \mathrm{Fe}^{\mathrm{III}}$ capsules prepared at $\mathrm{pH} 9$ were permeable to FITC-dextran of $M_{\mathrm{w}}$ of $2000 \mathrm{kDa}$ (Figures $3 \mathrm{~b}$, $\mathrm{S} 7$ ). The higher $\mathrm{pH}$ promoted deprotonation of TA, resulting in more negatively charged TA/Fe ${ }^{\mathrm{III}}$ capsules (Figure $3 \mathrm{c}$ ). The enhanced electrostatic repulsion between TA molecules and the increased propensity in the formation of tris-state $\mathrm{TA} / \mathrm{Fe}^{\mathrm{III}}$ complexes led to loosening of the internal molecular packing and enlargement of the pores in the film (Figure 3d).

The permeability differences arising from different $\mathrm{pH}$ suggest that the $\mathrm{TA} / \mathrm{Fe}^{\mathrm{III}}$ capsules can be engineered for programmable cargo encapsulation and release. In situ investigations were thus performed to examine the permeability states (i.e., "open" and "closed") of the TA/Fe $\mathrm{F}^{\mathrm{III}}$ capsules under different $\mathrm{pH}$ conditions
(Figure 4a). First, TA/Fe ${ }^{\mathrm{III}}$ capsules were incubated with FITCdextran at $\mathrm{pH} 9$ to load the cargo (Figure $4 \mathrm{~b}$ "Cargo loading $(\mathrm{pH}$ 9)"). While the loaded capsules remained in the "open" state, washing with water led to the escape of FITC-dextran from the capsules and fluorescence could not be detected (Figure S8a). However, reducing the $\mathrm{pH}$ to 4 after loading and subsequent washing with water led to most capsules being "closed", resulting in the encapsulation of FITC-dextran and a bright fluorescent ring (Figure 4b "Encapsulation ( $\mathrm{pH} 4$ )"). To confirm that the fluorescence was from the inner rim rather than the outer rim of the capsules, PS@TA/Fe $\mathrm{Fe}^{\mathrm{III}}$ core-shell particles were prepared and treated under the same condition as a control. Fluorescence was not detected (Figure S8b), implying that the cargo was encapsulated and remained on the inner surface. Finally, loading of the cargo inside the capsules was examined at $\mathrm{pH} 4$. As the capsules at $\mathrm{pH} 4$ were significantly less permeable (compared with those under alkaline conditions), only dim fluorescence was detected 
(Figure S8c, d). This further confirms the switchable "openclosed" state property of the capsules with $\mathrm{pH}$ regulation. The encapsulated cargo could be released by subsequently raising the $\mathrm{pH}$ (Figure 4b "Release (pH 9)").

To further investigate the cargo release kinetics, FITC-dextran encapsulated in $\mathrm{TA} / \mathrm{Fe}^{\mathrm{III}}$ capsules was released in situ at different $\mathrm{pH}$ over a period of time, and the percentage of cargo release was evaluated as the ratio of the mean fluorescence intensity measured at the capsule center to that measured on the rim. At $\mathrm{pH} 5$, the capsules exhibited low permeability, and only $10 \%$ of the cargo was released after 90 min (Figures 4c, S9). A more efficient release behavior was observed with increases in $\mathrm{pH}$. For example, $\sim 10 \%$ of the cargo was released after $10 \mathrm{~min}$ at $\mathrm{pH} 7$, whereas $50 \%$ of the cargo was released after $10 \mathrm{~min}$ at $\mathrm{pH} 9$. At $\mathrm{pH} 9$, the percentage of cargo release increased in a sustained fashion, reaching $80 \%$ in $90 \mathrm{~min}$ (Figures $4 \mathrm{c}, \mathrm{S} 9$ ). The recyclability of the "open-closed" states of the TA/Fe $/$ III capsules was also examined. As shown in Figures $4 \mathrm{~d}$ and S10, the cargo encapsulation-release profile could be repeated for at least 10 times. Moreover, the capsule permeability remained stable when exposed to a wide range of salt concentrations $(0-1000 \mathrm{mM}$, Figure S11). Considering the physiological $\mathrm{pH}$ and salinity in the human body, we envisage that MPN capsules could provide an effective platform for delivering drugs to target sites in alkaline conditions such as oral cavities ( $\mathrm{pH} 6.2-7.6),{ }^{31}$ the duodenum (pH 4.8-8.2), ${ }^{32}$ and the colon ( $\left.\mathrm{pH} 7.0-8.0\right) .{ }^{33}$ In addition, the recyclability and programmable permeability of MPN capsules could potentially be useful for catalysis and in smart anticorrosive coatings. ${ }^{34}$

\section{CONCLUSION}

In summary, we systemically demonstrated that the permeability of MPN capsules can be programmed through both intrinsic (precursor ratio, choice of phenolic ligand and metal ion) and extrinsic $(\mathrm{pH})$ parameters. Specifically, pairing $\mathrm{Fe}^{\mathrm{III}}$ with GA or pairing $\mathrm{Cu}^{\mathrm{II}}$ or $\mathrm{Al}^{\mathrm{III}}$ with $\mathrm{TA}$ led to capsule shrinkage and reduced capsule permeability. $\mathrm{pH}$ could modulate $\mathrm{TA} / \mathrm{Fe}^{\mathrm{III}}$ complexation states and intermolecular repulsion, thereby resulting in increased permeability at increased $\mathrm{pH}$. Importantly, the capsules showed reproducibly switchable "open" and "closed" states for programmable $\mathrm{pH}$-responsive cargo encapsulation and release. This study provides valuable insight into metal-organic systems, which can improve our understanding and control over the design of smart hybrid materials. In addition, the previously reported inherent properties (e.g., endosomal escape ${ }^{35}$ ), programmable permeability shown herein, coupled with controlled cargo release kinetics offer potential for the application of MPNs in numerous fields including drug delivery, catalysis, and smart anticorrosive coatings.

\section{EXPERIMENTAL SECTION}

Materials. TA, gallic acid monohydrate, $\mathrm{PG}$, iron(III) chloride hexahydrate $\left(\mathrm{FeCl}_{3} \cdot 6 \mathrm{H}_{2} \mathrm{O}\right)$, aluminum chloride hexahydrate $\left(\mathrm{AlCl}_{3} \cdot 6 \mathrm{H}_{2} \mathrm{O}\right)$, copper chloride tetrahydrate $\left(\mathrm{CuCl}_{2} \cdot 4 \mathrm{H}_{2} \mathrm{O}\right)$, sodium acetate (NaOAc), 3-(N-morpholino)propanesulfonic acid (MOPS), FITC, FITC-dextran of varying average molecular weights $(4,20,70,250,500$, and $2000 \mathrm{kDa})$, and (3-aminopropyl)triethoxysilane (APTES) were purchased from Sigma-Aldrich (USA). PS particles $(D=3.6 \pm 0.2 \mu \mathrm{m})$ were purchased from microParticles GmbH. Tetrahydrofuran (THF) and ethanol were purchased from Chem-Supply. All chemicals were used as received without further purification. Milli-Q water with a resistivity of greater than $18.2 \mathrm{M} \Omega \mathrm{cm}$ was obtained from a three-stage Millipore Milli-Q plus 185 purification system (Millipore Corporation, USA).

Material Characterization. DIC images were taken with an inverted Olympus IX71 microscope (Olympus, Japan). Fluorescence imaging was performed via CLSM. AFM experiments were conducted using a JPK NanoWizard II BioAFM instrument. Capsule thickness and roughness were measured from 10 different areas on each sample, and the data are reported as the mean value \pm standard deviation. UV-visible (UV-vis) absorption spectra were recorded on a Varian Cary 4000 UV-vis spectrophotometer. $\zeta$-Potential measurements were performed using a Zetasizer Nano ZS instrument (Malvern Instrument, UK).

Modification of Microscopic Glass Substrates. Modified glass substrates were used for the capsule permeability studies. For the modification of glass substrates, a $0.5 \%$ APTES solution was first prepared by dissolving $400 \mu \mathrm{L}$ of ATPES in $80 \mathrm{~mL}$ of ethanol. Aminated microscopic glass substrates were obtained by immersing the substrates in $0.5 \%$ APTES solution for $24 \mathrm{~h}$ and subsequent thorough rinsing with ethanol and Milli-Q water. The cleaned substrates were then dried under a stream of air before use.

Preparation of TA/Fe ${ }^{\mathrm{III}}$ Capsules at Different pH. All aqueous solutions were prepared freshly for immediate use. Before coating, $30 \mu \mathrm{L}$ of $10 \% \mathrm{w} / \mathrm{v}$ PS dispersion was washed twice with Milli-Q water via centrifugation $(2000 \mathrm{~g}, 1 \mathrm{~min})$ and subsequently dispersed in $440 \mu \mathrm{L}$ of Milli-Q water. Then, $5 \mu \mathrm{L}$ of $\mathrm{FeCl}_{3} \cdot 6 \mathrm{H}_{2} \mathrm{O}(37 \mathrm{mM})$ and $5 \mu \mathrm{L}$ of TA $(24 \mathrm{mM})$ were added successively to the PS dispersion at room temperature $\left(25^{\circ} \mathrm{C}\right)$ followed by brief vortexing and sonication. The $\mathrm{pH}$ of the mixed dispersion was adjusted by adding $500 \mu \mathrm{L}$ of MOPS (100 mM,

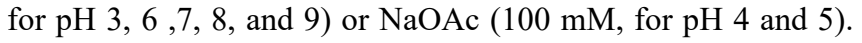
The mixed dispersion was vortexed for $1 \mathrm{~min}$ and allowed to sit undisturbed for $5 \mathrm{~min}$ to achieve sufficient film formation and adherence. The coated particles were then washed three times with $10 \mathrm{mM}$ buffer at the corresponding $\mathrm{pH}$ (MOPS for $\mathrm{pH} 3,6$, 7, 8, and 9; $\mathrm{NaOAc}$ for $\mathrm{pH} 4$ and 5) by centrifugation (2000 $\mathrm{g}, 1$ min). During each washing step, the supernatant was removed, and the suspension was briefly vortexed and sonicated to avoid particle aggregation. The pellet was redispersed in approximately $100 \mu \mathrm{L}$ of Milli-Q water after the final wash for template removal. To obtain TA/Fe ${ }^{\text {III }}$ capsules, $800 \mu \mathrm{L}$ of THF was added dropwise to the particle dispersion with a brief vortex. An additional $800 \mu \mathrm{L}$ of THF was added to dilute the suspension and the particles were incubated with THF for at least $3 \mathrm{~h}$ to dissolve the template. Then, the capsules were washed twice with THF (2000 $\mathrm{g}, 3 \mathrm{~min}$ ), and the remaining THF was removed by subsequent washing three times with buffer $(10 \mathrm{mM}$, desired $\mathrm{pH})(2000 \mathrm{~g}, 3$ $\min )$.

Preparation of TA/AI ${ }^{\mathrm{III}}$ and TA/Cu${ }^{\mathrm{II}}$ Capsules. The washed PS pellet was dispersed in $440 \mu \mathrm{L}$ of Milli-Q water. Then, $5 \mu \mathrm{L}$ of $\mathrm{AlCl}_{3} \cdot 6 \mathrm{H}_{2} \mathrm{O}(37 \mathrm{mM})$ or $\mathrm{CuCl}_{2} \cdot 4 \mathrm{H}_{2} \mathrm{O}(37 \mathrm{mM})$ and $5 \mu \mathrm{L}$ of TA $(24 \mathrm{mM})$ were added successively to the PS dispersion at room temperature $\left(25^{\circ} \mathrm{C}\right)$ followed by brief vortexing and sonication. The $\mathrm{pH}$ of the aforementioned dispersions was controlled to be the same by introducing $500 \mu \mathrm{L}$ of NaOAc $(100 \mathrm{mM}, \mathrm{pH}$ 5). Subsequent washing and template removal were performed as described for the preparation of $\mathrm{TA} / \mathrm{Fe}^{\mathrm{III}}$ capsules except that washing was performed with Milli-Q water instead of $10 \mathrm{mM}$ buffer.

Preparation of GA/Fe $\mathrm{Fe}^{\mathrm{III}}$ and PG/Fe ${ }^{\mathrm{III}}$ Capsules. For the synthesis of $\mathrm{GA} / \mathrm{Fe}^{\mathrm{III}}$ and $\mathrm{PG} / \mathrm{Fe}^{\mathrm{III}}$ capsules, the amount of GA and 
PG added was controlled so that the number of moles of the phenolic groups was the same as that in $5 \mu \mathrm{L}$ of TA $(24 \mathrm{mM})$. To prepare GA/Fe $\mathrm{FII}^{\mathrm{III}}$ coating: $5 \mu \mathrm{L} \mathrm{FeCl}_{3} \cdot 6 \mathrm{H}_{2} \mathrm{O}(37 \mathrm{mM})$ and $50 \mu \mathrm{L}$ of GA (4 mg mL $\mathrm{mL}^{-1}, 24 \mathrm{mM}$ ) were successively added followed by brief vortexing and sonication. To prepare $\mathrm{PG} / \mathrm{Fe}^{\mathrm{III}}$ coating: the precursors were changed to $5 \mu \mathrm{L} \mathrm{FeCl}_{3} \cdot 6 \mathrm{H}_{2} \mathrm{O}(37 \mathrm{mM})$ and $5 \mu \mathrm{L}$ of PG (29.6 mg mL $\left.\mathrm{mL}^{-1}, 240 \mathrm{mM}\right)$. Then, $500 \mu \mathrm{L}$ of $\mathrm{NaOAc}$ (100 mM, pH 5) was added to the precursor solution to adjust the $\mathrm{pH}$, followed by washing and template removal as per the same protocol described in Preparation of TA/AlIII and TA/Cu $\mathrm{Cu}^{I I} \mathrm{Cap}$ sules.

In Situ FITC-Dextran Permeability Study. To examine capsule permeability, $200 \mu \mathrm{L}$ of an MPN-coated PS suspension was dropped onto the modified microscopic glass substrate, followed by standing for $5 \mathrm{~min}$. The glass substrate was then immersed in THF for $1 \mathrm{~h}$. The remaining THF was removed by immersing twice in $10 \mathrm{mM}$ buffer (desired $\mathrm{pH}$ ) or Milli-Q water (Scheme $\mathrm{S} 1)$. Then, $200 \mu \mathrm{L}$ of FITC-dextran $\left(1 \mathrm{mg} \mathrm{mL}^{-1}\right.$ in solutions at the desired $\mathrm{pH} ; M_{\mathrm{w}} 4,20,70,250,500$, and $2000 \mathrm{kDa}$ ) was added to the capsule area on the glass substrate and incubated for 10 min. The capsules $(n=100)$ were examined by CLSM. Capsules with dark interiors were regarded as impermeable, whereas those with interiors with the same fluorescence intensity as the outer environment were considered to be permeable.

In Situ Cargo Encapsulation and Release Study. For the cargo encapsulation and release studies, $400 \mu \mathrm{L}$ of FITC-dextran ( $1 \mathrm{mg} \mathrm{mL}{ }^{-1}, 250 \mathrm{kDa}$ ) dissolved in $10 \mu \mathrm{M} \mathrm{NaOH}(\mathrm{pH}$ 9) was added to the capsule area on the glass substrate and incubated for $10 \mathrm{~min}$. Then, FITC-dextran was encapsulated by rinsing and incubating with $\mathrm{NaOAc}(100 \mathrm{mM}, \mathrm{pH} 4)$ for at least $10 \mathrm{~min}$. To release the cargo, the treated area was rinsed with Milli-Q water followed by incubation with $100 \mathrm{mM}$ buffer of corresponding $\mathrm{pH}$ values. The capsules were imaged by CLSM after the desired period of time. The percentage of cargo release was calculated as the ratio of the mean fluorescence intensity measured at the capsule center to that measured on the rim. For the analysis, 100 capsules were measured for each sample, and the data are shown as the mean value \pm standard deviation.

In Situ Recyclability Study. FITC-dextran $\left(1 \mathrm{mg} \mathrm{mL}^{-1}, 250\right.$ $\mathrm{kDa}$ ) was encapsulated and released using the same method as that described in In Situ Cargo Encapsulation and Release Study. CLSM images were captured, and the ratio of the mean fluorescent intensity measured at the capsule center to the mean fluorescent intensity detected on the rim was calculated after each encapsulation and release operation. The mean value was reported while the standard deviation is shown as error bars. The "open-closed" operation was repeated for 10 times.

\section{ASSOCIATED CONTENT}

Supporting Information. Experimental details, molecular structure of phenolic ligands, characterization data, and CLSM images. This material is available free of charge via the Internet at http://pubs.acs.org.

\section{AUTHOR INFORMATION}

\section{Corresponding Author}

*E-mail: fcaruso@unimelb.edu.au.

\section{Author Contributions}

The manuscript was written through contributions of all authors. All authors have given approval to the final version of the manuscript.

\section{Notes}

The authors declare no competing financial interest.

\section{ACKNOWLEDGMENT}

This research was conducted and funded by the Australian Research Council Centre of Excellence in Convergent Bio-Nano Science and Technology (project number CE140100036). F.C. acknowledges the award of a National Health and Medical Research Council Senior Principal Research Fellowship (GNT1135806). This work was performed in part at the Materials Characterisation and Fabrication Platform (MCFP) at The University of Melbourne and the Victorian Node of the Australian National Fabrication Facility (ANFF). Smallangle X-ray scattering experiments were conducted at the Australian Synchrotron (ANSTO Facilities). We thank Yiyuan Han and Zhixing Lin for the helpful discussion.

\section{REFERENCES}

(1) Hou, X.; Hu, Y.; Grinthal, A.; Khan, M.; Aizenberg, J. Liquid-Based Gating Mechanism with Tunable Multiphase Selectivity and AntiFouling Behaviour. Nature 2015, 519, 70-73.

(2) Hou, X. Smart Gating Multi-Scale Pore/Channel-Based Membranes. Adv. Mater. 2016, 28, 7049-7064.

(3) Park, H. B.; Kamcev, J.; Robeson, L. M.; Elimelech, M.; Freeman, B. D. Maximizing the Right Stuff: The Trade-off Between Membrane Permeability and Selectivity. Science 2017, 356, eaab0530.

(4) Liu, M.; Nothling, M. D.; Webley, P. A.; Fu, Q.; Qiao, G. G. Postcombustion Carbon Capture Using Thin-Film Composite Membranes. Acc. Chem. Res. 2019, 52, 1905-1914.

(5) Tokarev, I.; Minko, S. Stimuli-Responsive Porous Hydrogels at Interfaces for Molecular Filtration, Separation, Controlled Release, and Gating in Capsules and Membranes. Adv. Mater. 2010, 22, 3446-3462.

(6) Sun, Z.; Wu, Q.; Ye, C.; Wang, W.; Zheng, L.; Dong, F.; Yi, Z.; Xue, L.; Gao, C. Nanovoid Membranes Embedded with Hollow Zwitterionic Nanocapsules for a Superior Desalination Performance. Nano Lett. 2019, 19, 2953-2959.

(7) Dardelle, G.; Jacquemond, M.; Erni, P. Delivery Systems for Low Molecular Weight Payloads: Core/Shell Capsules with Composite Coacervate/Polyurea Membranes. Adv. Mater. 2017, 29, 1606099.

(8) Wang, H.-C.; Grolman, J. M.; Rizvi, A.; Hisao, G. S.; Rienstra, C. M.; Zimmerman, S. C. pH-Triggered Release from Polyamide Microcapsules Prepared by Interfacial Polymerization of a Simple Diester Monomer. ACS Macro Lett. 2017, 6, 321-325.

(9) Dergunov, S. A.; Khabiyev, A. T.; Shmakov, S. N.; Kim, M. D.; Ehterami, N.; Weiss, M. C.; Birman, V. B.; Pinkhassik, E. Encapsulation of Homogeneous Catalysts in Porous Polymer Nanocapsules Produces Fast-Acting Selective Nanoreactors. ACS Nano 2016, 10, 11397-11406.

(10) Richardson, J. J.; Bjornmalm, M.; Caruso, F. Technology-Driven Layer-by-Layer Assembly of Nanofilms. Science 2015, 348, aaa2491.

(11) Drachuk, I.; Shchepelina, O.; Lisunova, M.; Harbaugh, S.; KelleyLoughnane, N.; Stone, M.; Tsukruk, V. V. pH-Responsive Layer-byLayer Nanoshells for Direct Regulation of Cell Activity. ACS Nano 2012, 6, 4266-4278.

(12) Ye, C.; Drachuk, I.; Calabrese, R.; Dai, H.; Kaplan, D. L.; Tsukruk, V. V. Permeability and Micromechanical Properties of Silk Ionomer Microcapsules. Langmuir 2012, 28, 12235-12244.

(13) Ye, C.; Shchepelina, O.; Calabrese, R.; Drachuk, I.; Kaplan, D. L.; Tsukruk, V. V. Robust and Responsive Silk Ionomer Microcapsules. Biomacromolecules 2011, 12, 4319-4325. 
(14) Zhong, Q.-Z.; Pan, S.; Rahim, M. A.; Yun, G.; Li, J.; Ju, Y.; Lin, Z.; Han, Y.; Ma, Y.; Richardson, J. J.; Caruso, F. Spray Assembly of Metal-Phenolic Networks: Formation, Growth, and Applications. ACS Appl. Mater. Interfaces 2018, 10, 33721-33729.

(15) Pan, S.; Guo, R.; Bertleff-Zieschang, N.; Li, S.; Besford, Q. A.; Zhong, Q.-Z.; Yun, G.; Zhang, Y.; Cavalieri, F.; Ju, Y.; Goudeli, E.; Richardson, J. J.; Caruso, F. Modular Assembly of Host-Guest MetalPhenolic Networks Using Macrocyclic Building Blocks. Angew. Chem. Int. Ed. 2020, 59, 275-280

(16) Alsbaiee, A.; Smith, B. J.; Xiao, L.; Ling, Y.; Helbling, D. E.; Dichtel, W. R. Rapid Removal of Organic Micropollutants from Water by a Porous Beta-Cyclodextrin Polymer. Nature 2016, 529, 190-194.

(17) Huang, F.; Liao, W. C.; Sohn, Y. S.; Nechushtai, R.; Lu, C. H.; Willner, I. Light-Responsive and pH-Responsive DNA Microcapsules for Controlled Release of Loads. J. Am. Chem. Soc. 2016, 138, 8936-8945

(18) Kim, J. W.; Lee, S. S.; Park, J.; Ku, M.; Yang, J.; Kim, S. H. Smart Microcapsules with Molecular Polarity- and Temperature-Dependent Permeability. Small 2019, 15, 1900434.

(19) Dignon, G. L.; Zheng, W.; Kim, Y. C.; Mittal, J. Temperature-Controlled Liquid-Liquid Phase Separation of Disordered Proteins. ACS Cent. Sci. 2019, 5, 821-830.

(20) Emilsson, G.; Sakiyama, Y.; Malekian, B.; Xiong, K.; Adali-Kaya, Z.; Lim, R. Y. H.; Dahlin, A. B. Gating Protein Transport in Solid State Nanopores by Single Molecule Recognition. ACS Cent. Sci. 2018, 4, $1007-1014$

(21) Song, Q.; Cao, S.; Pritchard, R. H.; Ghalei, B.; Al-Muhtaseb, S. A.; Terentjev, E. M.; Cheetham, A. K.; Sivaniah, E. Controlled Thermal Oxidative Crosslinking of Polymers of Intrinsic Microporosity towards Tunable Molecular Sieve Membranes. Nat. Commun. 2014, 5, 4813.

(22) Werner, J. G.; Deveney, B. T.; Nawar, S.; Weitz, D. A. Dynamic Microcapsules with Rapid and Reversible Permeability Switching. Adv. Funct. Mater. 2018, 28, 1803385.

(23) Krogsgaard, M.; Nue, V.; Birkedal, H. Mussel-Inspired Materials: Self-Healing through Coordination Chemistry. Chem. Eur. J. 2016, 22, 844-857.

(24) Lin, Z.; Zhou, J.; Cortez-Jugo, C.; Han, Y.; Ma, Y.; Pan, S.; Hanssen, E.; Richardson, J. J.; Caruso, F. Ordered Mesoporous MetalPhenolic Network Particles. J. Am. Chem. Soc. 2020, 142, 335-341

(25) Ejima, H.; Richardson, J. J.; Liang, K.; Best, J. P.; Van Koeverden, M. P.; Such, G. K.; Cui, J.; Caruso, F. One-Step Assembly of Coordination Complexes for Versatile Film and Particle Engineering. Science 2013, 341, 154-157.

(26) Guo, J.; Ping, Y.; Ejima, H.; Alt, K.; Meissner, M.; Richardson, J. J.; Yan, Y.; Peter, K.; von Elverfeldt, D.; Hagemeyer, C. E.; Caruso, F. Engineering Multifunctional Capsules through the Assembly of MetalPhenolic Networks. Angew. Chem. Int. Ed. 2014, 53, 5546-5551.

(27) Rahim, M. A.; Kristufek, S. L.; Pan, S.; Richardson, J. J.; Caruso, F. Phenolic Building Blocks for the Assembly of Functional Materials. Angew. Chem. Int. Ed. 2019, 58, 1904-1927.

(28) Park, J. H.; Kim, K.; Lee, J.; Choi, J. Y.; Hong, D.; Yang, S. H.; Caruso, F.; Lee, Y.; Choi, I. S. A Cytoprotective and Degradable MetalPolyphenol Nanoshell for Single-Cell Encapsulation. Angew. Chem. Int. Ed. 2014, 53, 12420-12425.

(29) Yun, G.; Besford, Q. A.; Johnston, S. T.; Richardson, J. J.; Pan, S.; Biviano, M.; Caruso, F. Self-Assembly of Nano- to Macroscopic MetalPhenolic Materials. Chem. Mater. 2018, 30, 5750-5758.

(30) Zhong, Q.-Z.; Li, S.; Chen, J.; Xie, K.; Pan, S.; Richardson, J. J.; Caruso, F. Oxidation-Mediated Kinetic Strategies for Engineering Metal-Phenolic Networks. Angew. Chem. Int. Ed. 2019, 58, 12563-12568.

(31) Baliga, S.; Muglikar, S.; Kale, R. Salivary pH: A Diagnostic Biomarker J. Indian Soc. Periodontol. 2013, 17, 461-465.

(32) Schmaljohann, D. Thermo- and pH-Responsive Polymers in Drug Delivery. Adv. Drug Delivery Rev. 2006, 58, 1655-1670.
(33) Khan, M. Z. I.; Prebeg, Z.; Kurjakovic, N. A pH-Dependent Colon Targeted Oral Drug Delivery System Using Methacrylic Acid Copolymers. J. Controlled Release 1999, 58, 215-222.

(34) Fu, J.; Chen, T.; Wang, M.; Yang, N.; Li, J.; Wang, Y.; Liu, X. Acid and Alkaline Dual Stimuli-Responsive Mechanized Hollow Mesoporous Silica Nanoparticles as Smart Nanocontainers for Intelligent Anticorrosion Coatings. ACS Nano 2013, 7, 11397-11408.

(35) Chen, J.; Li, J.; Zhou, J.; Lin, Z.; Cavalieri, F.; Czuba-Wojnilowicz, E.; Hu, Y.; Glab, A.; Ju, Y.; Richardson, J. J.; Caruso, F. Metal-Phenolic Coatings as a Platform to Trigger Endosomal Escape of Nanoparticles. ACS Nano 2019, 13, 11653-11664. 


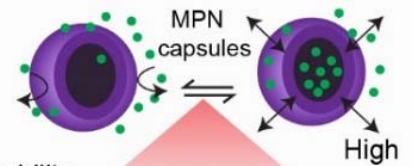

permeability Programmable permeability

\begin{tabular}{|l|l|l|l|}
\hline $\begin{array}{l}\text { Intrinsic } \\
\text { modulation }\end{array}$ & $\begin{array}{l}\text { Extrinsic } \\
\text { modulation }\end{array}$ \\
\hline $\begin{array}{l}\text { Building } \\
\text { blocks }\end{array}$
\end{tabular}




\section{University Library}

\section{- M M N E R VA A gateway to Melbourne's research publications}

Minerva Access is the Institutional Repository of The University of Melbourne

Author/s:

Chen, J;Pan, S;Zhou, J;Zhong, Q-Z;Qu, Y;Richardson, JJ;Caruso, F

Title:

Programmable Permeability of Metal-Phenolic Network Microcapsules

Date:

2020-08-25

Citation:

Chen, J., Pan, S., Zhou, J., Zhong, Q. -Z., Qu, Y., Richardson, J. J. \& Caruso, F. (2020).

Programmable Permeability of Metal-Phenolic Network Microcapsules. Chemistry of

Materials, 32 (16), pp.6975-6982. https://doi.org/10.1021/acs.chemmater.0c02279.

Persistent Link:

http://hdl.handle.net/11343/241962 